\title{
Numerical evaluation of mode I/II SIF of quasi-brittle materials using cracked semi-circular bend specimen
}

\author{
A. S. Fayed ${ }^{a^{*}}$
}

${ }^{a}$ Materials Engineering Department, Faculty of Engineering, Zagazig University, Zagazig, Egypt On leave for the Mechanical Engineering Department, Faculty of Engineering, Jazan University, KSA

\begin{tabular}{l}
\hline A R T I C L EI N F O \\
\hline Article history: \\
Received 26 October, 2017 \\
Accepted 14 January 2018 \\
Available online \\
14 January 2018 \\
\hline Keywords: \\
Three-point bending \\
Cracked semi-disc \\
Modes I and II stress intensity \\
factors \\
Finite element method
\end{tabular}

\section{Introduction}

Ductile and brittle failures are two commonly mechanisms of failure in engineering structures and components. Ductile mechanism frequently arises in ductile materials. Large scale yielding typically proceeds that type of facture. Quite the opposite, brittle fracture is a rapid type of failure. Brittle materials, e.g. ceramics, rocks, concrete, etc., are exposed to brittle fracture with no considerable plastic deformation. Subsequently, brittle fracture results in catastrophic consequences.

Stress concentration arises from cracks, notches, defects and surface scratches. It affects the performance and reliability of engineering applications and structures. The fracture toughness of brittle materials is reduced due the existence of pre-existing cracks (Kato \& Nishioka, 2005). Intensive

\footnotetext{
* Corresponding author.

E-mail addresses: amrfayed@yahoo.com (A. S. Fayed)

\begin{abstract}
An in-house finite element code was utilized to evaluate mode I/II stress intensity factor (SIF) of an edge cracked semi-circular disc subjected to three-point bending. The specimen was considered as an isotropic and homogeneous material. Relative span length ratios of 0.3 to 0.8 analyzed with crack angles up to $60^{\circ}$ in steps of $5^{\circ}$. At the same crack length, mode I SIF decreases with increasing crack angle or decreasing the span length. The range of pure mode II decreases with increasing the span length. For the same crack length, the crack angle corresponding to the transition from a mixed mode I/II to a pure mode II increases with increasing the relative span length ratio. On the contrary, that angle decreases with increasing the crack length for the same span length. Good agreement has been generally obtained with relevant results found in the literature.
\end{abstract}

C) 2018 Growing Science Ltd. All rights reserved. 
theoretical and experimental studies have frequently devoted their effort to brittle failure in engineering structures and components with cracks and/or notches (Akbardoost \& Ayatollahi, 2014; Aliha et al., 2014, 2016; Aliha et al., 2017; Ayatollahi et al., 2015; Fakhri et al., 2017; Fayed, 2008, 2017; Fayed et al., 2008; Hammouda et al., 2003a, 2004, 2002; Razmi \& Mirsayar, 2017; Wei et al., 2016, 2017a,b). It was experimentally noticed that crack extension occurred in mode I rather than shear mode or mixed mode. Many investigations were typically focused in opening mode failure for crack growth (Alfano et al., 2009; Akbardoost et al., 2014; Erdogan \& Sih, 1963; Fowell et al., 1995; Lim et al., 1994; Yoshihara \& Kawamura, 2006; Zhang, 2002; Zhou et al., 2012). The cracks in brittle materials are often vulnerable to compressive loading rather than tensile loading (Ke et al., 2008).

Many service failures occur due to the existence of cracks subjected to loads, which develop a state of mixed-mode by virtue of their orientation with respect to the loading axis. Many applications of brittle materials are showing mixed mode and/or mode II fracture. Engineering designers are extremely interested in crack growth in such materials. Therefore, many different test configurations were proposed to properly evaluate mixed mode and/or mode II fracture in brittle materials. Among the wellknown test specimens is the "Semi-Circular Bend" (SCB) specimen under three-point bending (Lim et al., 1994). The SCB specimen has a simple geometry, loading arrangement, the capability of applying various mode mixity by changing the pre-crack inclination angle relative to the applied load (Ayatollahi \& Aliha, 2006; Chong \& Kuruppu, 1984; Kuruppu \& Chong, 2012; Rashidi Moghaddam et al., 2017). It provides a simple and effective technique for conducting mixed mode fracture tests in brittle materials (Aliha et al., 2010, 2016, 2017; Ayatollahi et al., 2006; Elghazel et al., 2016; Ameri et al., 2012, 2016; Fathipour Azar et al., 2015; Kataoka et al., 2017; Wei et al., 2016 Aliha \& Ayatollahi, 2013; Aliha \& Saghafi, 2013; Aliha \& Fattahi Amirdehi, 2017; Fakhri et al., 2018; Roy et al., 2017a,b; Abd-Elhady 2013; Mirsayar et al., 2017; Funatsu et al., 2014; Artamendi \& Khalid, 2006). Nevertheless, the crack properties such as location, size, inclination and loading configuration have a pronounced effect on the crack extension. In this paper, an in-house finite element analysis was carried out to address the fracture parameters of an edge cracked semi-circular specimen under three-point loading. Wide range of semidisc geometries were invoked to evaluate mode I/II SIF under different load mixities.

\section{Present analysis}

An in house developed finite element code was utilized to evaluate mode I/II SIF (pure mode, mixed mode and pure mode II) considering frictionless crack surfaces in SCB specimens. A Fortran module was coded to generate special mesh model. The model has precise sequences of sorting and numbering of contact pairs along the crack surfaces. The model has the capability to change semi disc dimensions, crack size, crack inclination angle to predict the crack path. The fracture behaviour of a SCB having a slant crack with smooth surfaces under mixed modes was invoked. The plane strain state was assumed. PMMA or Plexiglas is a model brittle material which is used frequently by the fracture toughness researchers (Ayatollahi et al., 2011; Ayatollahi \& Aliha, 2007a,b; Saghafi et al., 2013; Aliha et al., 2016, 2017). Therefore, the present finite element utilized PMMA as the semi-disc material. The mechanical properties of PMMA are as follows: modulus of elasticity, $E=2.95 \mathrm{GPa}$, and Poisson's ratio, $v=0.35$. An applied load, $P$, of $2 \mathrm{kN}$ was used for the analyses. The specimens were assumed to be homogeneous, isotropic and elastic material. As shown in Fig. 1, the SCB specimen was $50 \mathrm{~mm}$ in radius, $R$, and a thickness, $t$, of $5 \mathrm{~mm}$. The semi-disc specimen is placed on two bottom supports of distance $2 S$. Several $S / R$ ratios in the range of 0.3 to 0.8 with step of 0.1 were assumed. Cracks of length to semi-disc radius ratios, $a / R$, of $0.1,0.2,0.3,0.4,0.5$ and 0.6 were analysed with an assumption of crack inclination angle, $\beta$, ranging from $0^{\circ}$ to $60^{\circ}$ in steps of $5^{\circ}$ measured clock wise from the loading direction (see Fig. 1). It should be mentioned that for larger crack angles $\beta>60^{\circ}$, a small wedge of a material beneath the crack forms and can be simply fractured (Chong \& Kuruppu, 1984; Whittaker, Singh, \& Sun, 1992). Subsequently, the current numerical results were limited to $\beta \leq 60^{\circ}$. 


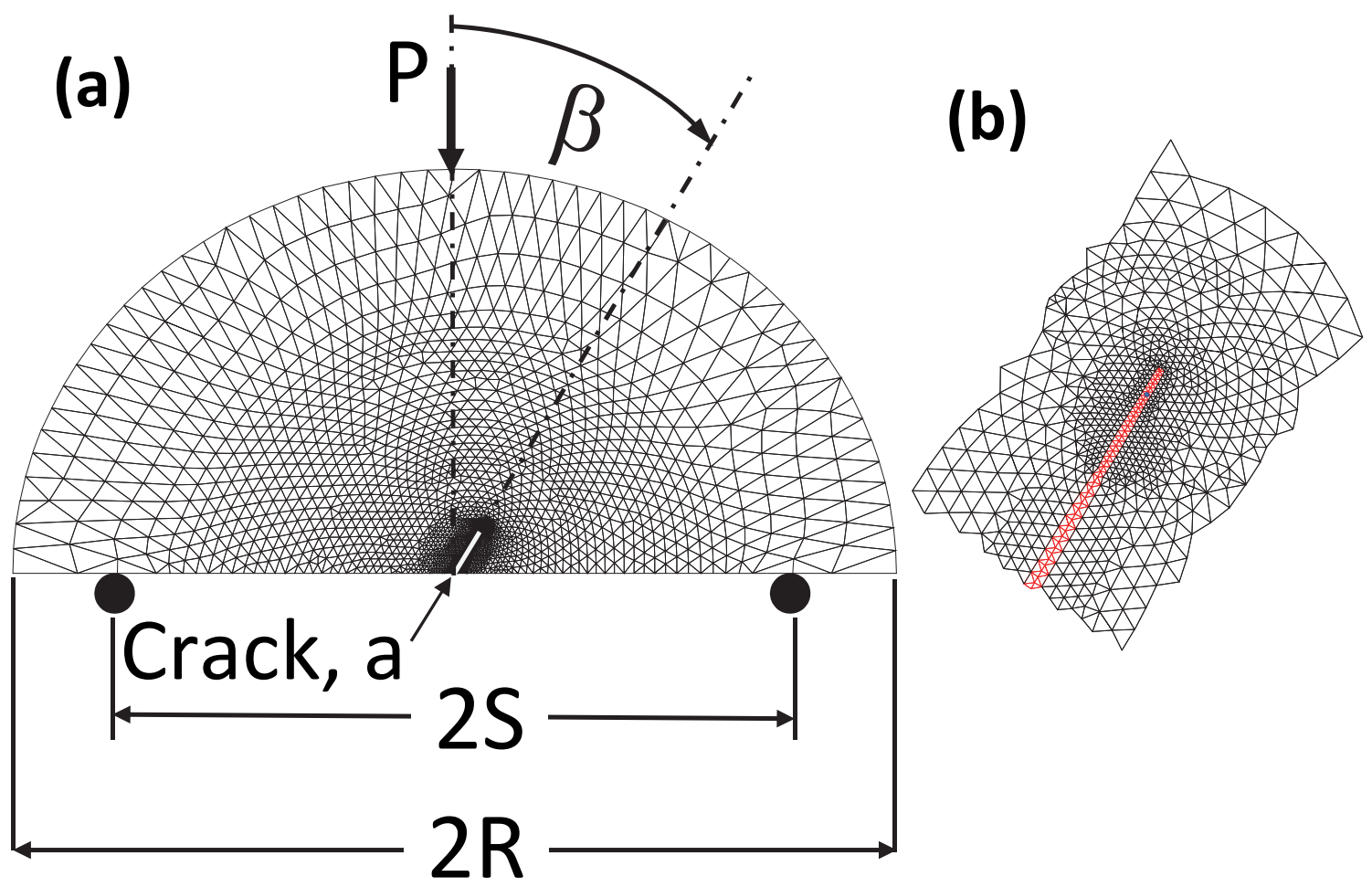

Fig. 1. The analysed cracked semi-disc; (a) Typical finite element mesh of the semi-disc with the invoked geometry and loading regime, (b) A typical example of the final mesh refinement around the crack tip

A brief description of the methods employed in computing the SIFs for mixed mode and mode II crack tip displacements is summarized as follows. For closed crack tips, the strain energy, $U$, corresponding to the applied diametral compressive load was individually computed for two cracks of lengths $a$ and $a+d a$, i.e. $U_{a}$ and $U_{a}+d a$. The strain energy released if the disc ends were fixed would have been $d U\left(\approx U_{a}+d a-U_{a}\right)$. The mode II SIF, $K_{I I}$, was then calculated by considering the resulting strain energy release rate, $G_{I I}(=d U / d a / t)$, i.e. $K_{I I}\left(E^{\prime} G I I\right)^{0.5}$, where $E^{\prime}=E /\left(1-v^{2}\right)$ for the plane strain state. For opened crack tips, the crack could artificially advance at the instant of maximum load with a step corresponding to one element. Cracking was carried out by an incremental release of the two-crack tip reaction forces, $F_{t}$ and $F_{n}$. The forces $F_{t}$ and $F_{n}$ were parallel and normal to the crack surfaces respectively. During that de-coupling process, the strain energy released, $d U$, due to the relaxation of $F_{t}$ and $F_{n}$ were respectively $d U_{t}$ and $d U_{n}$. This enabled the computation of the mode I SIF, $K_{I}=\left(E^{\prime} d U_{n} / d a / t\right)^{0.5}$, and $K_{I I}=\left(E^{\prime} d U_{t} / d a / t\right)^{0.5}$. The dimensionless stress intensity factors, $Y_{I}$ and $Y_{I I}$, were estimated using the following expressions for the present analysed SCB specimen:

$$
\begin{aligned}
Y_{j} & =\frac{K_{j}}{K_{o}}, \quad j=I, I I \\
K_{o} & =\frac{P \sqrt{\pi a}}{2 R t} .
\end{aligned}
$$

All the meshes were generated to have constant strain triangular elements. Fig. 1 shows a typical example of the present idealization. A meshing technique was applied to construct a nodal pair (two 
nodes with the same coordinates connected to each other) on the upper and lower crack surfaces. The crack location is shown as a white line. Depending on the analysed case, the number of elements and the degree of freedom were altered due to the generated mesh. No singular element was attempted to simulate the singularity of the crack-tip stress field. Instead, a fine mesh was constructed around the crack tip. That idealization proved its adequacy in similar analyses (Hammouda et al., 2002, 2003a, 2003b, 2004, 2007, 2017; Fayed, 2008; Fayed et al., 2008).

The ratio of the smallest element size, $d a$, and crack length, $a$, was kept equal to 0.008 . Hammouda and Fayed (2017) found that $d a / a=0.008$ was sufficient to get an accurate solution for their problem. The ratio $d a / a$ in the present work was decided based on the results of similar pilot exercises in which the several $d a / a$ ratios $0.002,0.004,0.006$ and 0.008 were also invoked to compare the resulting computed stress intensity factors. Fig. 2 shows the numerical normalized mode I and mode II SIFs, $Y_{I}$ and $Y_{I I}$ respectively in the case of $a / R=0.5$ and $S / R=0.67$ at different crack inclination angles, $\beta$. The SIFs computed by all four ratios were in excellent agreement with one another. It was found that the present $d a / a$ ratio reduced the execution time with a maximum difference of less than $0.01 \%$. Table 1 summarizes the comparative values between the four examined $d a / a$ ratios. These idealizations will be further used in some future works by the author to simulate relevant crack path of cracked semi-disc.

Table 1. Converging of the present $d a / a$ ratio as compared to other sizes at $a / R=0.5$ and $S / R=0.67$

\begin{tabular}{ccccc}
\hline & \multicolumn{4}{c}{ Relative crack increment to crack length ratio, da/a } \\
& 0.002 & 0.004 & 0.006 & 0.008 \\
\hline Elements \# & 18818 & 8850 & 5692 & 4352 \\
Nodes \# & 9842 & 4670 & 3033 & 2333 \\
$Y_{I}$, Error \% & 0.001 & 0.01 & 0.01 & \\
$Y_{I I}$ Error \% & 0.011 & 0.0102 & 0.0102 & \\
\hline
\end{tabular}

Executing time relative to that of $d a / a=0.008, \mathrm{X}$

$276.3 \quad 17.8 \quad 2.7$

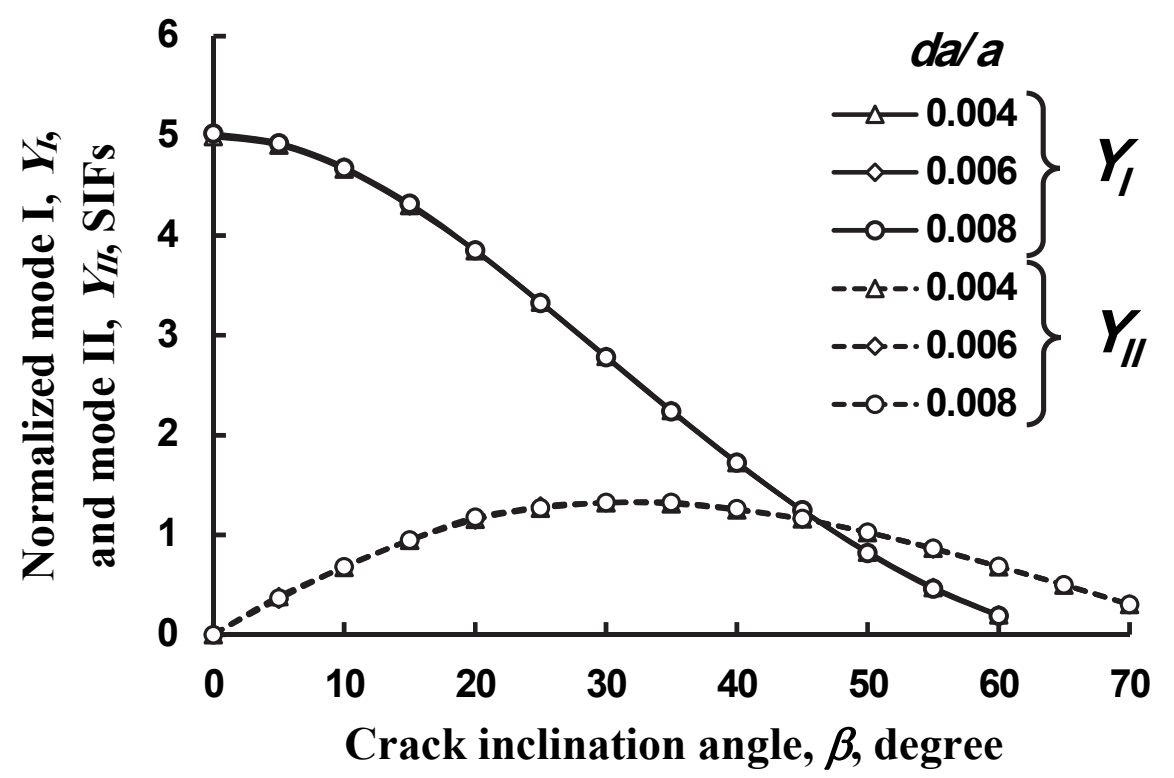

Fig. 2. Evaluation of normalized mode I/II SIF for different crack increment ratio, $d a / a$, and different crack angles, $\beta$, at $a / R=0.5$ and $S / R=0.67$ 


\section{Results and discussion}

To validate the current numerical idealization, a comparison between the present numerical results and some of the relevant data found in the literature is represented in Fig. 3. Only mode I SIF equal to or greater than zero were considered in the present analysis. Fig. 3 demonstrates the variation of mode I and mode II geometry factors, respectively, $Y_{I}$ and $Y_{I I}$, versus the crack inclination angle, $\beta, a / R=0.5$ and $S / R=0.5 \&$ 0.67. Literature data found in Lim et al. (1993) and Ayatollahi and Aliha (2004) were considered. Fig. 3 shows that $Y_{I}$ becomes nearly zero at crack angle $\beta \approx 40^{\circ}$ and $65^{\circ}>\beta>60^{\circ}$ for $S / R$; $=0.5$ and 0.67 , respectively, hence the specimen is subjected to pure mode II. Lim et al. (1993) and Ayatollahi and Aliha (2004) mentioned that the crack angles of pure II were, respectively, $\beta ;=63^{\circ}$ and $40.5^{\circ}$ for $S / R$; $=0.67$ and 0.5 . Therefore, there is a good consistency between the present numerical results and those obtained from the literature. Although $Y_{I I}$ were calculated differently for fully opened cracks and closed cracks regimes, there was no significant difference between the corresponding values obtained. Accordingly, the present numerical simulation methodology gives precise results and can be effectively used for the crack analysis of SCB specimens.

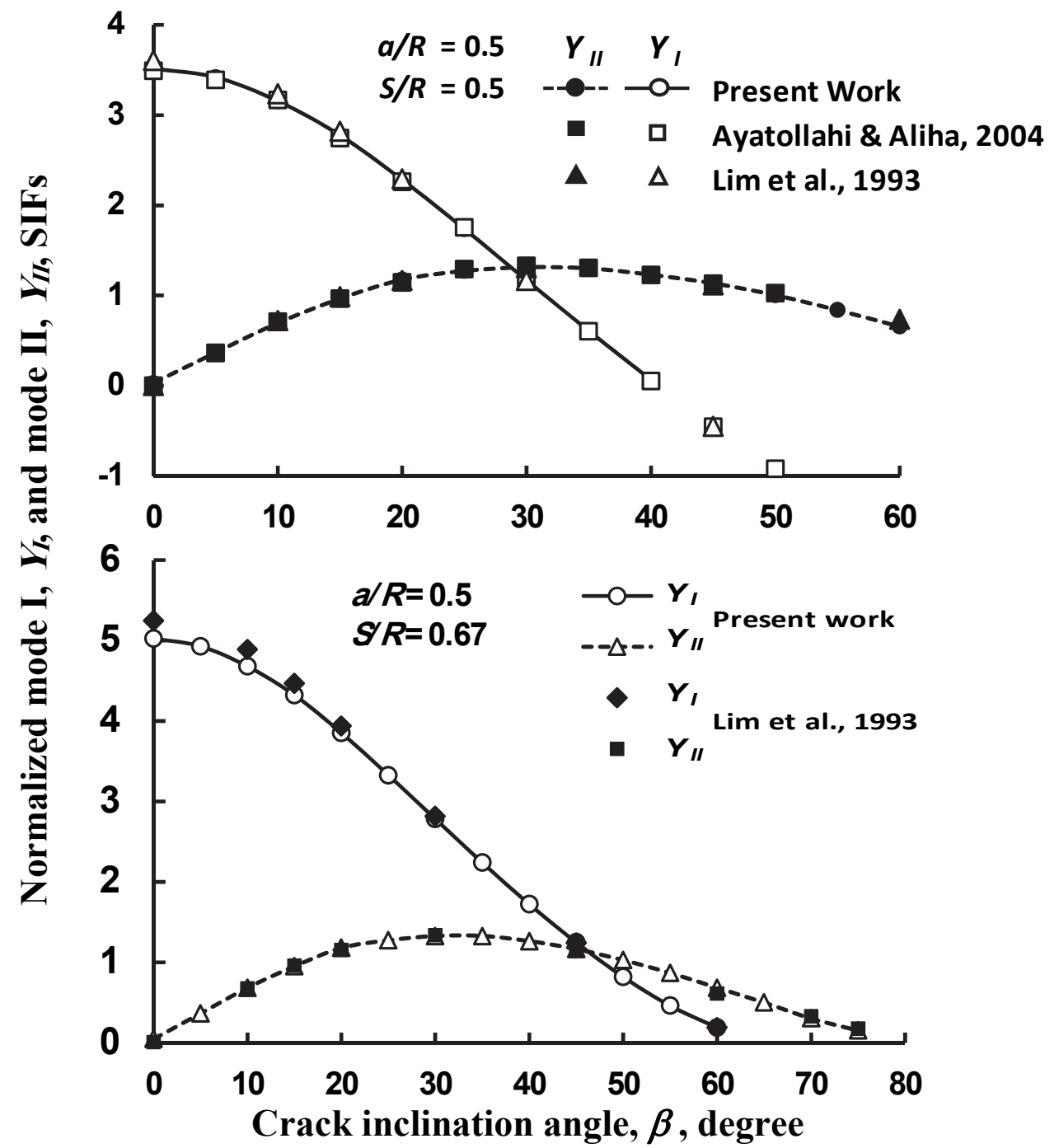

Fig. 3. Comparison of some present geometry factors $Y_{I}$ and $Y_{I I}$ of semi-disc under three-point bending having an inclined crack, $\beta$, with those available in the literature 
Fig. 4 and Fig. 5 describe the numerical results of the normalized mode I and mode II SIFs, respectively, $Y_{I}$ and $Y_{I I}$ with $S / R=0.3$ to $0.8, \beta=0^{\circ}$ to $60^{\circ}$ and $a / R=0.1$ to 0.6 . A total of 624 of different SCB geometries were examined to cover a wide range of the normalized mixed mode I/II SIFs. For the same crack angle, Fig. 4 shows that $Y_{I}$ increases with increasing $S / R$. Also, for the same crack length, $Y_{I}$ decreases with increasing the crack angle. As the crack angle increases, the crack tip becomes near to region of the SCB supports, thereby, mode I component diminishes and mode II component becomes more dominant. This trend is more obvious for longer crack lengths in the SCB of smaller span lengths.

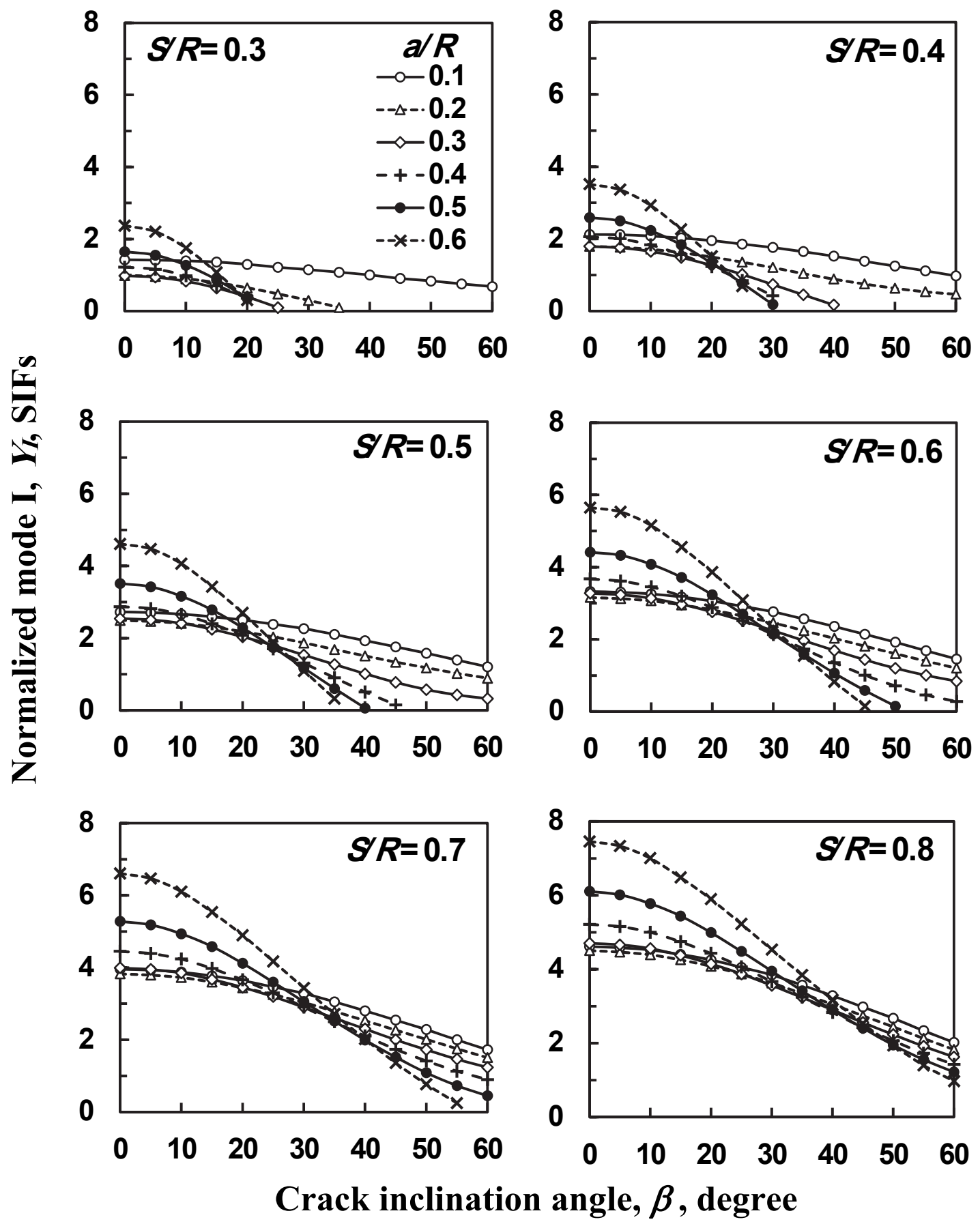

Fig. 4. Variation of normalized mode I SIF, $Y$, for different crack lengths, $a / R$, and crack angles, $\beta$, at various span length, $S / R$ 


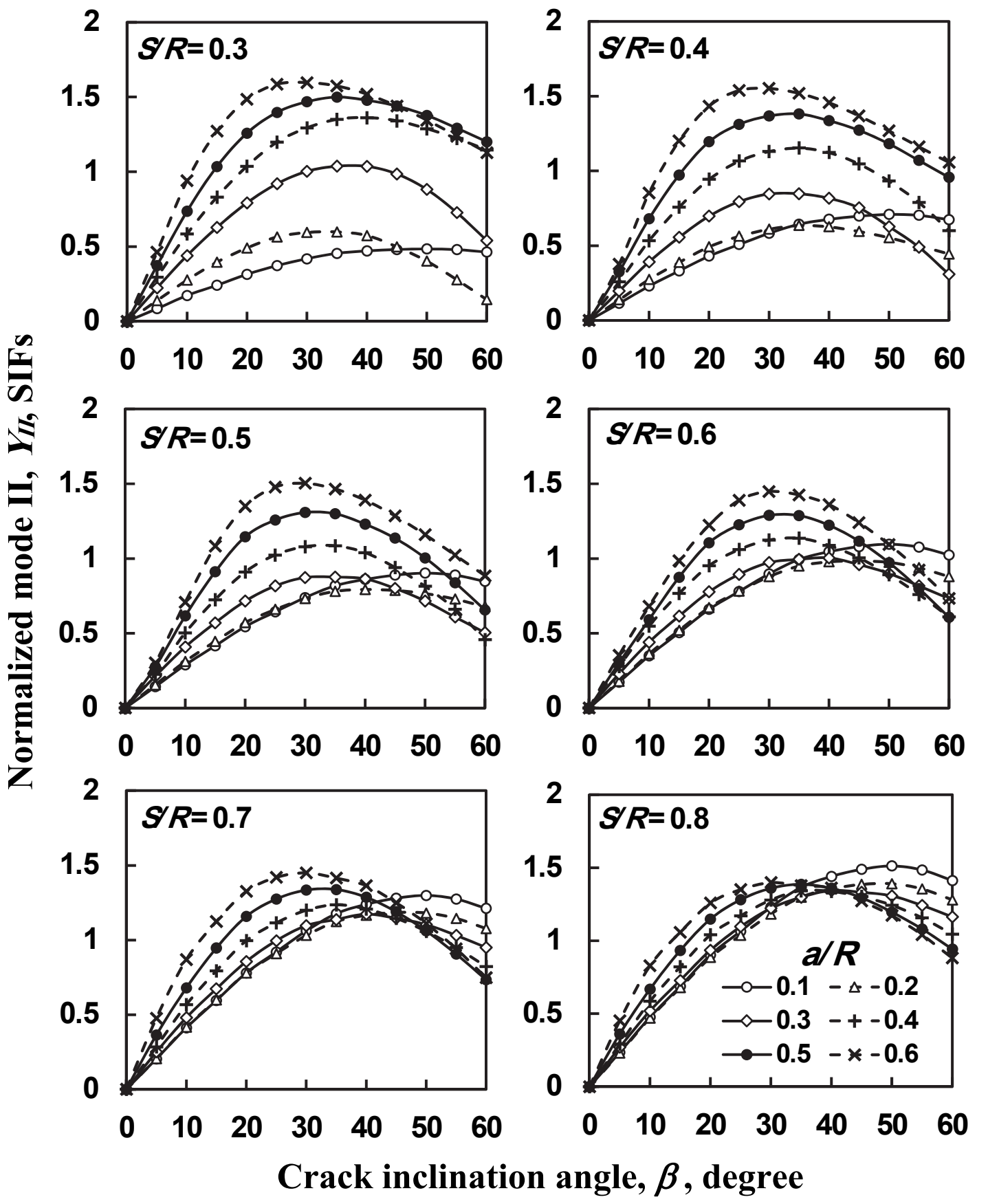

Fig. 5. Variation of normalized mode II SIF, $Y_{I I}$, for different crack lengths, $a / R$, and crack angles, $\beta$, at various span to disc radius ratio, $S / R$

The crack tip deformation changes from pure mode I at $\beta=0^{\circ}$ followed by mixed mode loading at $\beta>0^{\circ}$ and, finally, a pure mode II loading dominates due to the SCB geometry. Pure mode II arises due to the closed crack surfaces associated with a negative $K_{I}$. However, only positive $K_{I}$ was considered in the present analysis. Fig. 4 depicts that as the span length ratio increases, the range of pure mode II SIF diminishes. Thereby, the range of positive mode I SIF component increases apparently with increasing $S / R$. For the same $S / R$, the range of positive mode I shrinks with increasing the crack length. As the crack angle increases, the rate of $Y_{I}$ variation from maximum value at $\beta=0^{\circ}$ to zero value at $\beta_{I I}$ increases with increasing $a / R$. $\beta_{I I}$ is the angle at which pure mode is achieved. The above 
observations are in consistent agreement with Lim et al. (1993). Fig. 5 shows that for the same crack length as $\beta$ increases $Y_{I I}$ increases to reach a maximum followed by a decrease in $Y_{I I}$.

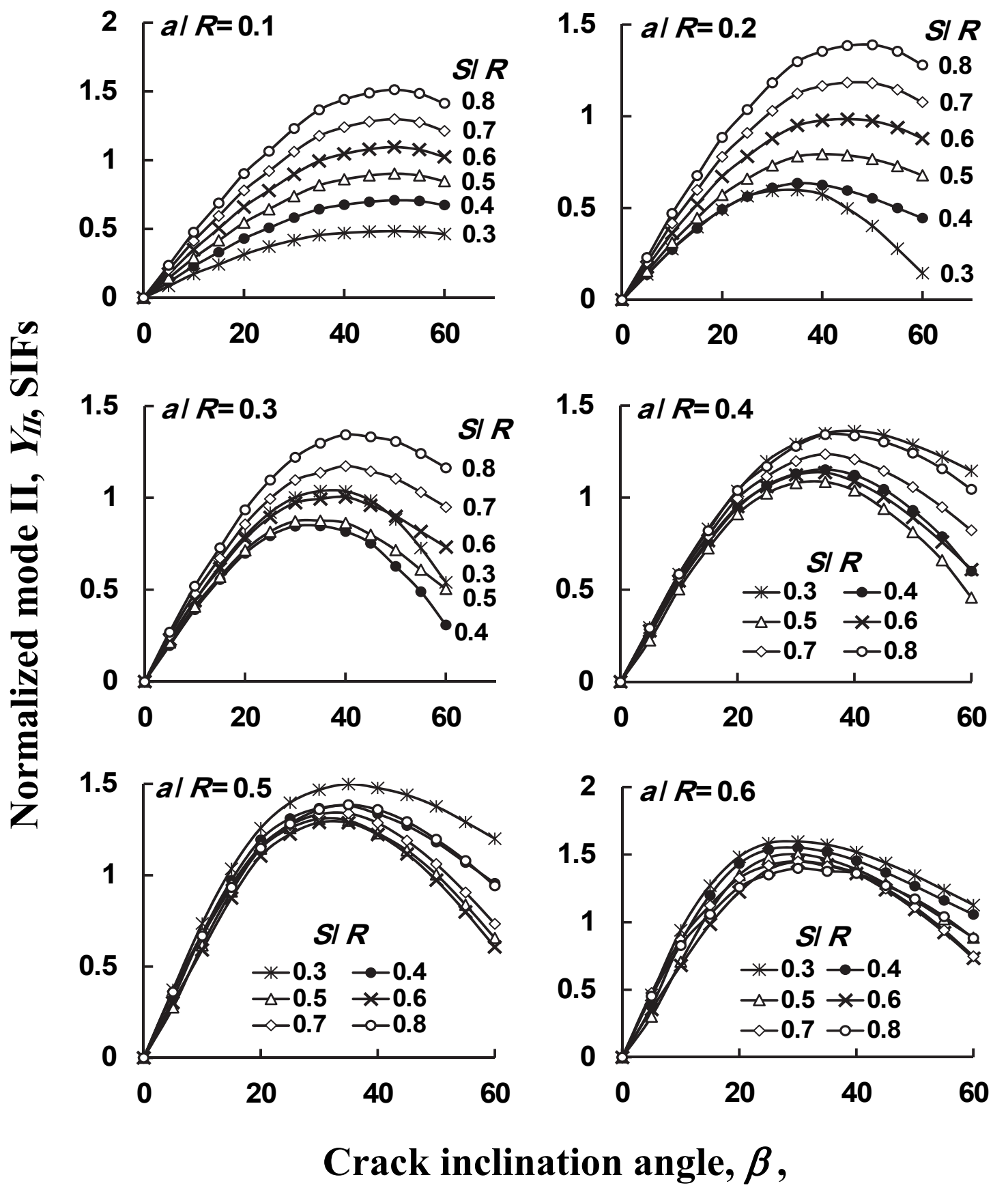

Fig. 6. Effect of span length, $S / R$, on the normalized mode II SIF, $Y_{I I}$, for different crack lengths, $a / R$ at different crack angles, $\beta$

Fig. 6 illustrates that for short cracks, i.e. $a / R=0.1$ and 0.2 , as the span length increases, mode II SIF increases. For $a / R=0.1$ and 0.2 , the crack tip deformation is controlled by mixed mode loading for all range of the investigated $S / R$ and $\beta$ except for $a / R=0.2$ at $S / R=0.3$. On the other hand, for the same $a / R$, the cracks that have region of closed crack surfaces within a range of $\beta, Y_{I I}$ decreases with increasing the span length. But with further increase of $S / R$, the crack behavior changes from pure mode II into mixed mode with an opened crack surface. Subsequently, for crack surfaces under mixed mode loading, $Y_{I I}$ increases with increasing $S / R$. Fig. 6 explained obviously these results. 
To capture the angle at which pure mode II starts, $\beta_{I I}$, an additional 135 semi-disc geometries were examined with smaller crack angle range. In other words, crack angle step of $0.5^{\circ}$ were utilized in the transition range between mixed mode to pure mode II. For all the range of $a / R$ and $S / R$, Pure mode I is achieved always at $\beta=0^{\circ}$. While pure mode II is attained at different crack angles depending on $a / R$ and $S / R$. The calculated $\beta_{I I}$ for the different $S / R, a / R$ geometries is shown in Table 2. Table 2 depicts that $\beta_{I I}$ increases with increasing $S / R$ or decreasing $a / R$. Ayatollahi and Aliha (2004) found that to provide pure mode II with $\beta<60^{\circ}$, the maximum allowable values of $S / R$ were $0.47,0.565,0.65$ and 0.725 , respectively, for $a / R=0.3,0.4,0.5$ and 0.6 . Their findings are in consistent with the present results.

Table 2. Comparison of $\beta_{I I}$ obtained in the present work for different values of span length, $S / R$, and relative crack length, $a / R$, with similar results found in the literature

\begin{tabular}{|c|c|c|c|c|c|c|c|c|c|c|}
\hline \multirow{2}{*}{$a / R$} & \multicolumn{3}{|l|}{ Present work } & \multicolumn{7}{|c|}{ Ayatollahi \& Aliha, 2004} \\
\hline & $S / R=0.3$ & 0.4 & 0.5 & 0.6 & 0.7 & 0.3 & 0.4 & 0.5 & 0.6 & 0.7 \\
\hline 0.6 & 22 & 29.5 & 37.5 & 47 & 58 & & & 36.7 & 46.2 & 57.5 \\
\hline 0.5 & 23.5 & 31.5 & 41 & 52 & & & & 40.5 & 52.1 & \\
\hline 0.4 & 25 & 35 & 47.5 & & & & 35.1 & 47.5 & & \\
\hline 0.3 & 27 & 43.5 & & & & 26.5 & 42.8 & & & \\
\hline 0.2 & 38 & & & & & & & & & \\
\hline 0.1 & & & & & & & & & & \\
\hline
\end{tabular}

\section{Conclusions}

An in-house finite element code was utilized to evaluate the fracture behaviour of an isotropic homogeneous semi-disc containing an edge crack under three-point bending loading. Corresponding modes I and II SIFs have been successfully computed and validated for relative crack length ratios of $0.1,0.2,0.3,0.4,0.5$ and 0.6 , crack angles in the range from $0^{\circ}$ to $60^{\circ}$ and span length ratios of 0.3 , $0.4,0.5,0.6,0.7$ and 0.8 . The current study leads to the following conclusions.

1- Mode I SIF decreases with increasing crack angle or decreasing the span length at the same crack length.

2- As the span length increases, the range of pure mode II SIF diminishes

3- For the same crack length. the crack angle corresponding to the transition from a mixed mode I/II to a pure mode II increases with increasing the relative span length ratio.

4- On the contrary, that angle decreases with increasing the crack length for the same span length.

5- Good agreement has been generally obtained with the relevant results found in the literature.

\section{References}

Abd-Elhady, A. (2013). Mixed mode I/II stress intensity factors through the thickness of disc type specimens. Engineering Solid Mechanics, 1(4), 119-128.

Akbardoost, J., \& Ayatollahi, M. R. (2014). Experimental analysis of mixed mode crack propagation in brittle rocks: The effect of non-singular terms. Engineering Fracture Mechanics, 129, 77-89.

Akbardoost, J., Ayatollahi, M. R., Aliha, M. R. M., Pavier, M. J., \& Smith, D. J. (2014). Size-dependent fracture behavior of Guiting limestone under mixed mode loading. International Journal of Rock Mechanics and Mining Sciences, 71, 369-380.

Alfano, M., Furgiuele, F., Leonardi, A., Maletta, C., \& Paulino, G. H. (2009). Mode I fracture of 
adhesive joints using tailored cohesive zone models. International Journal of Fracture, 157(1-2), 193-204.

Aliha, M. R. M., Ayatollah, M. R., Smith, D. J., \& Pavier, M. J. (2010). Geometry and size effects on fracture trajectory in a limestone rock under mixed mode loading. Engineering Fracture Mechanics, 77(11), 2200-2212.

Aliha, M. M., Behbahani, H., Fazaeli, H., \& Rezaifar, M. H. (2014). Study of characteristic specification on mixed mode fracture toughness of asphalt mixtures. Construction and Building Materials, 54, 623-635.

Aliha, M. R. M., Bahmani, A., \& Akhondi, S. (2016). Mixed mode fracture toughness testing of PMMA with different three-point bend type specimens. European Journal of Mechanics, A/Solids, 58, 148162.

Aliha, M. R. M., Heidari-Rarani, M., Shokrieh, M. M., \& Ayatollahi, M. R. (2012). Experimental determination of tensile strength and K (IC) of polymer concretes using semi-circular bend(SCB) specimens. Structural Engineering and Mechanics, 43(6), 823-833.

Aliha, M. R. M., \& Ayatollahi, M. R. (2013). Two-parameter fracture analysis of SCB rock specimen under mixed mode loading. Engineering Fracture Mechanics, 103, 115-123.

Aliha, M. R. M., \& Saghafi, H. (2013). The effects of thickness and Poisson's ratio on 3D mixed-mode fracture. Engineering Fracture Mechanics, 98, 15-28.

Aliha, M. R. M., \& Fattahi Amirdehi, H. R. (2017). Fracture toughness prediction using Weibull statistical method for asphalt mixtures containing different air void contents. Fatigue \& Fracture of Engineering Materials \& Structures, 40(1), 55-68.

Aliha, M. R. M., Berto, F., Bahmani, A., \& Gallo, P. (2017). Mixed mode I/II fracture investigation of Perspex based on the averaged strain energy density criterion. Physical Mesomechanics, 20(2), 149156.

Ameri, M., Mansourian, A., Pirmohammad, S., Aliha, M. R. M., \& Ayatollahi, M. R. (2012). Mixed mode fracture resistance of asphalt concrete mixtures. Engineering Fracture Mechanics, 93, 153167.

Ameri, M., Nowbakht, S., Molayem, M., \& Aliha, M. R. M. (2016). Investigation of fatigue and fracture properties of asphalt mixtures modified with carbon nanotubes. Fatigue \& fracture of engineering materials \& structures, 39(7), 896-906.

Artamendi, I., \& Khalid, H. A. (2006). A comparison between beam and semi-circular bending fracture tests for asphalt. Road Materials and Pavement Design, 7(sup1), 163-180.

Ayatollahi, M. R., \& Aliha, M. R. M. (2007a). Wide range data for crack tip parameters in two disctype specimens under mixed mode loading. Computational materials science, 38(4), 660-670.

Ayatollahi, M. R., \& Aliha, M. R. M. (2007b). Fracture toughness study for a brittle rock subjected to mixed mode I/II loading. International Journal of Rock Mechanics and Mining Sciences, 44(4), 617 624.

Ayatollahi, M. R., \& Akbardoost, J. (2013). Size effects in mode II brittle fracture of rocks. Engineering Fracture Mechanics, 112-113, 165-180.

Ayatollahi, M. R., Aliha, M. R. M., \& Hassani, M. M. (2006). Mixed mode brittle fracture in PMMAan experimental study using SCB specimens. Materials Science and Engineering: A, 417(1), 348356.

Ayatollahi, M. R., \& Aliha, M. R. M. (2004). Fracture parameters for a cracked semi-circular specimen. International Journal of Rock Mechanics and Mining Sciences, 41(SUPPL. 1), 1-6.

Ayatollahi, M. R., \& Aliha, M. R. M. (2006). On determination of mode II fracture toughness using semi-circular bend specimen. International Journal of Solids and Structures, 43(17), 5217-5227.

Ayatollahi, M. R., Aliha, M. R. M., \& Saghafi, H. (2011). An improved semi-circular bend specimen for investigating mixed mode brittle fracture. Engineering Fracture Mechanics, 78(1), 110-123.

Chong, K. P., \& Kuruppu, M. D. (1984). New specimen for fracture toughness determination for rock and other materials. International Journal of Fracture, 26(2).

Elghazel, A., Taktak, R., \& Bouaziz, J. (2016). Combined numerical and experimental mechanical characterization of a calcium phosphate ceramic using modified Brazilian disc and SCB specimen. 
Materials Science and Engineering A, 670, 240-251.

Erdogan, F., \& Sih, G. C. (1963). On the crack extension in plane loading and transverese shear. Journal Basic Engr., 85(4), 519-527.

Fakhri, M., Amoosoltani, E., \& Aliha, M. R. M. (2017). Crack behavior analysis of roller compacted concrete mixtures containing reclaimed asphalt pavement and crumb rubber. Engineering Fracture Mechanics, 180, 43-59.

Fakhri, M., Kharrazi, E. H., Aliha, M. R. M., \&Berto, F. (2018). The effect of loading rate on fracture energy of asphalt mixture at intermediate temperatures and under different loading modes. Frattura ed Integrità Strutturale, 12(43), 113-132.

Funatsu, T., Kuruppu, M., \& Matsui, K. (2014). Effects of temperature and confining pressure on mixed-mode (I-II) and mode II fracture toughness of Kimachi sandstone. International Journal of Rock Mechanics and Mining Sciences, 67, 1-8.

Fathipour Azar, H., Choupani, N., Afshin, H., \& Hamidzadeh Moghadam, R. (2015). Effect of mineral admixtures on the mixed-mode (I/II) fracture characterization of cement mortar: CTS, CSTBD and SCB specimens. Engineering Fracture Mechanics, 134, $20-34$.

Fayed, A. S. (2002). Mixed mode crack tip deformation due to multi-axial cyclic loading. Ph.D. Thesis; Department of Mechanical Eng; Al-Azhar University; Cairo; Egypt;

Fayed, A. S. (2008). Size Effect of Asymmetric Four Point Bend Specimen on Crack Propagation in Ceramics. Ain Shams University, Faculty of Engineering Journal, 1(1), 227-237.

Fayed, A. S. (2017). Numerical analysis of mixed mode I/II stress intensity factors of edge slant cracked plates. Engineering Solid Mechanics, 5(1), 61-70.

Fayed, A. S., Sherbini, H. S., \& Sallam, H. E. M. (2008). Crack Path in Steel Fiber Reinforced Concrete Composite under Mixed Mode. Ain Shams University, Faculty of Engineering Journal, 1(1), 1726.

Fowell, R. J., Hudson, J. A., C., X., J., F. C., \& X., Z. (1995). Suggested method for determining mode I fracture toughness using cracked chevron notched Brazilian disc (CCNBD) specimens. International Journal of Rock Mechanics and Mining Sciences and Geomechanics Abstracts, 32(7), $322 \mathrm{~A}$.

Hammouda, M.M.I. \& Fayed A.S. (2017). Modes I/II SIF of a diametrically compressed Brazilian disc having a central inclined crack with frictional surfaces. Fatigue Fract Eng Mater Struct; 1-13.

Hammouda, M. M. I., Fayed, A. S., \& Sallam, H. E. M. (2002). Mode II stress intensity factors for central slant cracks with frictional surfaces in uniaxially compressed plates. International Journal of Fatigue, 24(12), 1213-1222.

Hammouda, M. M. I., Fayed, A. S., \& Sallam, H. E. M. (2003a). Stress intensity factors of a shortly kinked slant central crack with frictional surfaces in uniaxially loaded plates. International Journal of Fatigue, 25(4), 283-298.

Hammouda, M. M. I., Fayed, A. S., \& Sallam, H. E. M. (2003b). Simulation of mixed mode I/II cyclic deformation at the tip of a short kinked inclined crack with frictional surfaces. International Journal of Fatigue, 25(8), 743-753.

Hammouda, M. M. I., Fayed, A. S., \& Sallam, H. E. M. (2004). Stress intensity factors of a central slant crack with frictional surfaces in plates with biaxial loading. International Journal of Fracture, $129(2), 141-148$.

Hammouda, M. M. I., Pasha, R. A., \& Fayed, A. S. (2007). Modelling of cracking sites/development in axial dovetail joints of aero-engine compressor discs. International Journal of Fatigue, 29(1), 3048.

Kataoka, M., Mahdavi, E., Funatsu, T., Takehara, T., Obara, Y., Fukui, K., \& Hashiba, K. (2017). Estimation of Mode I Fracture Toughness of Rock by Semi-Circular Bend Test under Confining Pressure Condition. Procedia Engineering, 191, 886-893.

Kato, T., \& Nishioka, T. (2005). Analysis of micro-macro material properties and mechanical effects of damaged material containing periodically distributed elliptical microcracks. International Journal of Fracture, 131(3), 247-266. 
Ke, C. C., Chen, C. S., \& Tu, C. H. (2008). Determination of fracture toughness of anisotropic rocks by boundary element method. Rock Mechanics and Rock Engineering, 41(4), 509-538.

Kuruppu, M. D., \& Chong, K. P. (2012). Fracture toughness testing of brittle materials using semicircular bend (SCB) specimen. Engineering Fracture Mechanics, 91, 133-150.

Lim, I. L., Johnston, I. W., \& Choi, S. K. (1993). Stress intensity factors for semi-circular specimens under three-point bending. Engineering Fracture Mechanics, 44(3), 363-382.

Lim, I. L., Johnston, I. W., Choi, S. K., \& Boland, J. N. (1994). Fracture testing of a soft rock with semi-circular specimens under three-point bending. Part 1-mode I. International Journal of Rock Mechanics and Mining Sciences and, 31(3), 185-197.

Mirsayar, M., Shi, X., \& Zollinger, D. (2017). Evaluation of interfacial bond strength between Portland cement concrete and asphalt concrete layers using bi-material SCB test specimen. Engineering Solid Mechanics, 5(4), 293-306.

Rashidi Moghaddam, M., Ayatollahi, M. R., \& Berto, F. (2017). Mixed mode fracture analysis using generalized averaged strain energy density criterion for linear elastic materials. International Journal of Solids and Structures, 120, 1339-1351.

Roy, D. G., Singh, T. N., Kodikara, J., \& Das, R. (2017a). Effect of water saturation on the fracture and mechanical properties of sedimentary rocks. Rock Mechanics and Rock Engineering, 50(10), 2585-2600.

Roy, D. G., Singh, T. N., \& Kodikara, J. (2017b). Influence of joint anisotropy on the fracturing behavior of a sedimentary rock. Engineering Geology, 228, 224-237.

Razmi, A., \& Mirsayar, M. M. (2017). On the mixed mode I/II fracture properties of jute fiberreinforced concrete. Construction and Building Materials, 148, 512-520.

Saghafi, H., Zucchelli, A., \& Minak, G. (2013). Evaluating fracture behavior of brittle polymeric materials using an IASCB specimen. Polymer Testing, 32(1), 133-140.

Wei, M. D., Dai, F., Xu, N. W., Liu, J. F., \& Xu, Y. (2016). Experimental and Numerical Study on the Cracked Chevron Notched Semi-Circular Bend Method for Characterizing the Mode I Fracture Toughness of Rocks. Rock Mechanics and Rock Engineering, 49(5), 1595-1609.

Wei, M. D., Dai, F., Xu, N. W., Liu, Y., \& Zhao, T. (2017a). Fracture prediction of rocks under mode I and mode II loading using the generalized maximum tangential strain criterion. Engineering Fracture Mechanics, 186, 21-38.

Wei, M. D., Dai, F., Xu, N. W., Zhao, T., \& Liu, Y. (2017b). An experimental and theoretical assessment of semi-circular bend specimens with chevron and straight-through notches for mode I fracture toughness testing of rocks. International Journal of Rock Mechanics and Mining Sciences, 99, 28-38.

Whittaker, B. N., Singh, R. N., \& Sun, G. (1992). Rock fracture mechanics : principles, design, and applications. Elsevier.

Yoshihara, H., \& Kawamura, T. (2006). Mode I fracture toughness estimation of wood by DCB test. Composites Part A: Applied Science and Manufacturing, 37(11), 2105-2113.

Zhang, Z. X. (2002). An empirical relation between mode I fracture toughness and the tensile strength of rock. International Journal of Rock Mechanics and Mining Sciences, 39(3), 401-406.

Zhou, Y. X., Xia, K., Li, X. B., Li, H. B., Ma, G. W., Zhao, J., ... Dai, F. (2012). Suggested methods for determining the dynamic strength parameters and mode-I fracture toughness of rock materials. International Journal of Rock Mechanics and Mining Sciences, 49, 105-112.

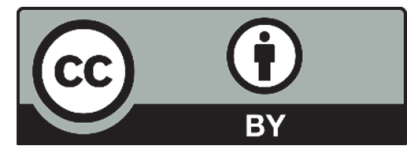

(C) 2018 by the authors; licensee Growing Science, Canada. This is an open access article distributed under the terms and conditions of the Creative Commons Attribution (CC-BY) license (http://creativecommons.org/licenses/by/4.0/). 